\title{
CORROSION FATIGUE CRACK PROPAGATION RATE CHARACTERISTICS FOR WELDABLE SHIP AND OFFSHORE STEELS WITH REGARD TO THE INFLUENCE OF LOADING FREQUENCY AND SALTWATER TEMPERATURE
}

Marek Jakubowski

Gdańsk University of Technology, Poland

\begin{abstract}
After Vosikovsky (1975), the corrosion fatigue crack growth rate (CFCGR) characteristics have been divided into three regions. The region-III rates are very close to mechanical fatigue crack growth rates. CFCGR formulae, including the long-crack length effect (in region I only), the loading frequency effect (in region II only), and the saltwater temperature effect, have been proposed. It has been assumed that CFCGR is proportional to $f^{-k}$, where $f$ is the loading frequency and $k$ is a constant. The averaged $k$-value for all steels of yield stress (YS) below $500 \mathrm{MPa}$, usually with ferrite-pearlite microstructures, is higher than that for YS > 500 MPa, usually with quenched and tempered microstructures. The temperature effect does not appear in region I below room temperature. In the remaining cases, that is, in region I for elevated temperatures and in region II for both low and elevated temperatures, the CFCGR increases with increasing temperature. Under a potential of $-0.8 \mathrm{~V}$, a long-crack-length effect, qualitatively similar to analogous effect for free corrosion conditions, appears.
\end{abstract}

Keywords: corrosion fatigue,crack growth rate,crack length,saltwater temperature,frequency effect,ship and offshore steels

\section{NOMENCLATURE}

a - the crack length $[\mathrm{m}]$

$a_{n} \quad-$ net length of crack (as measured from the notch root) $[\mathrm{mm}]$

$C_{I I} \quad-$ a coefficient in the relation between $\beta$ and $\Delta K$ in region II $\left[\left(\mathrm{MPa} \mathrm{m}^{1 / 2}\right)^{n}\right]$

$\mathrm{d} a / \mathrm{dN}_{\text {air }}$ - mechanical fatigue crack growth rate $[\mathrm{m} / \mathrm{c}]$

$\mathrm{d} a / \mathrm{d} N_{e}-$ corrosion fatigue crack growth rate at a loading frequency of $0.1 \mathrm{~Hz}$ and room temperature $[\mathrm{m} / \mathrm{c}]$

$\mathrm{d} a / \mathrm{dN}_{f}$ - corrosion fatigue crack growth rate at a frequency $f[\mathrm{~m} / \mathrm{c}]$

$\mathrm{d} a / \mathrm{dN}_{f T}-$ corrosion fatigue crack growth rate at a frequency $f$ and temperature $T[\mathrm{~m} / \mathrm{c}]$

$\mathrm{d} a / \mathrm{d}_{T}-$ corrosion fatigue crack growth rate at a temperature $T[\mathrm{~m} / \mathrm{c}]$

$\mathrm{d} a / \mathrm{dN}_{T r}$ - corrosion fatigue crack growth rate at room temperature $T_{r}[\mathrm{~m} / \mathrm{c}]$

$E_{\text {act }} \quad$ - activation energy $[\mathrm{kJ} / \mathrm{mol}]$

$f \quad$ - loading frequency $[\mathrm{Hz}]$

$k-\quad-$ exponent of the loading frequency effect [-]

$n-$ exponent in the relation between $\beta$ and $\Delta K$ in region II [-]
$R \quad-$ the stress ratio in a loading cycle $[-]$

$R_{G} \quad$ - universal gas constant $=8.3143[\mathrm{~J} / \mathrm{K}]$

$T \quad$ - temperature $[\mathrm{K}]$

$\mathrm{T}_{{ }^{\circ} \mathrm{C}} \quad-$ temperature $\left[{ }^{\circ} \mathrm{C}\right]$

$T_{r} \quad$ - room temperature $[\mathrm{K}]$

$T_{r^{\circ} \mathrm{C}} \quad-$ room temperature $\left[{ }^{\circ} \mathrm{C}\right]$

UTS - ultimate tensile strength [MPa]

YS - yield strength of material [MPa]

$\beta-$ - relative effect of environment, that is, the ratio (CFCGR)/(FCGR) [-]

$\Delta K \quad-$ stress intensity factor range $\left[\mathrm{MPa} \mathrm{m}^{1 / 2}\right]$

$\Delta K_{I-I I}-$ stress intensity factor range value at the border between regions I and II of the characteristics

$\Delta K_{I I-I I I}-$ a constant representing the value of $\Delta K$ for which the relative effect of the environment for region II equals 1

$\Delta P \quad-$ load range $[\mathrm{MPa}]$

abbreviations

CFCGR - corrosion fatigue crack growth rate

CT - compact tension specimen

FCGR - (mechanical) fatigue crack growth rate

SEN - single edge notched specimen 


\section{INTRODUCTION}

Users and designers of welded marine structures have a choice between different methods of lifespan predictions, comprehensively discussed by Vázquez et al. [1]. Some of the methods consider the total life of a structural component as a sum of progressive crack initiation steps, some as a process of short and then long crack propagation, but numerous methods consider it as the sum of the phases of crack initiation and propagation. In some approaches to lifespan calculations, the short crack propagation period can be considered as the crack initiation period and calculated by low cycle fatigue methods or analysed "using a small crack correction to the large crack rate model" [1]. In such cases, fracture mechanics crack-propagation characteristics for long cracks are useful. The characteristics are much more complex for corrosion fatigue than for mechanical fatigue and they are the focus of interest of the present paper.

The characteristics of the corrosion fatigue crack propagation rate $\mathrm{d} a / \mathrm{d} N_{\mathrm{e}}$ versus the stress intensity factor range $\Delta K$ for long cracks have been divided into three regions (I, II, and III) by Vosikovsky [2]. The division of the corrosion fatigue crack propagation rate diagram for the regions proposed by Vosikovsky is shown schematically in Fig. 1a.

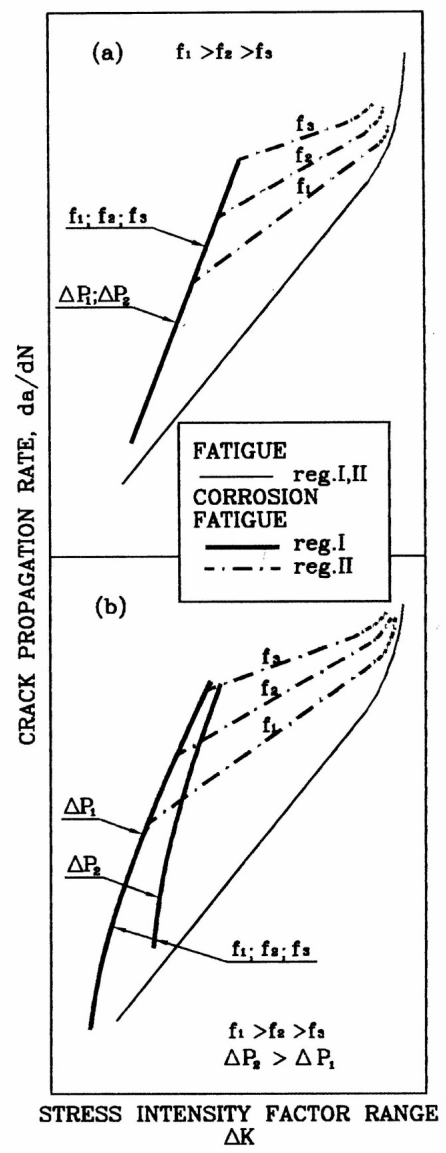

Fig.1. Schematic diagrams of the characteristics of the fatigue and corrosion fatigue crack growth rate under free corrosion potential for different loading frequencies $(f)$ and load levels $(\Delta P)$ : (a) traditional, i.e. established for a long time by Vosikovsky [2]; (b) proposed by the author [3], i.e. described by relations (1) and (2).
Below, region III has been omitted because in this region the corrosion fatigue crack propagation is usually dominated by purely mechanical factors and the corrosion fatigue crack growth rates (CFCGRs) in region III do not differ much from fatigue crack growth rates (FCGRs) $\mathrm{d} a / \mathrm{d} N_{\text {air }}$. Therefore, the present paper is focused on the regions I and II. The only differences between the regions noted by Vosikovsky were the value of the slope $m$ (which is higher for region I) and the effect of the loading frequency, which is negligible for region I and evident in region II. The present author has analysed his own CFCGR test results for a steel under different but constant values of the stress intensity factor range $\Delta K$ and has described them by the following empirical formulae [3]:

$$
\frac{\mathrm{d} a}{\mathrm{~d} N_{e}}=\frac{\mathrm{d} a}{\mathrm{~d} N_{\text {air }}} \cdot \beta=\frac{\mathrm{d} a}{\mathrm{~d} N}_{\text {air }} \cdot 1.15\left(a_{n}\right)^{0.5}
$$

and

for region I

$$
\begin{gathered}
\frac{\mathrm{d} a}{\mathrm{~d} N_{e}}=\frac{\mathrm{d} a}{\mathrm{~d} N_{\text {air }}} \cdot \beta={\frac{\mathrm{d} a}{\mathrm{~d} N_{\text {air }}}} \cdot C_{I I} \cdot(\Delta K)^{-n}=\frac{\mathrm{d} a}{\mathrm{~d} N_{\text {air }}} \cdot\left(\frac{\Delta K}{\Delta K_{I I-I I I}}\right)^{-n} \\
\text { for region II }
\end{gathered}
$$

where $\Delta K$ is the stress intensity factor range and $a_{n}$ is the net-length of the crack (in millimetres) as measured from the notch root, while the nominal length $(a)$ of the crack includes both $a_{n}$ and the length of the notch. The values $C_{I I}$ and $n$ are constants. Value $\Delta K_{I I-I I I}$ is an alternative form of constant $C_{I I}$ , that is, the value of $\Delta K$ for which $\beta=1$ in region II. In the above equations, value of $\beta$ is called the relative effect of the environment and is equal to $\left(\mathrm{d} a / \mathrm{d} N_{e}\right) /\left(\mathrm{d} a / \mathrm{d}_{a i r}\right)$.

A specific effect of the crack's net length for long-corrosionfatigue cracks (in paper [3]) for $a_{n}>1 \mathrm{~mm}$ ) is described by Equation (1). This has been called the long-crack-length effect. The effect is inverse to the short crack length effect, which is well-known (e.g. $[4,5])$ and will not be considered in the present paper. In the light of later considerations [6], Equation (1) is well-founded theoretically, and therefore the previously [3] proposed alternative form containing the term $\log \left(a_{n}\right)$ will not be considered in the present paper. The values of the crack net-length and the corresponding $\Delta K_{I-I I}$, which cuts off region II from region I, can be calculated as the intersection of the characteristics of regions I and II.

The above equations have been used for the description of different CFCGR curves [3]. All types of salt water solutions, that is, $3.5 \% \mathrm{NaCl}$ solution, artificial sea water, and natural sea water, were considered jointly. From the CFCGR point of view, the main difference between both sea waters and $\mathrm{NaCl}$ solution is the presence of $\mathrm{Ca}^{2+}$ and $\mathrm{Mg}^{2+}$ in both former waters. $\mathrm{CaCO}_{3}$ and $\mathrm{Mg}(\mathrm{OH})_{2}$ can be deposited on the crack walls and increase the crack closure effect, influencing the crack growth rates, but not in a free corrosion regime. The kinetics of the deposition of both compounds increases along with the potential drop. Scott and Silvester's [7] investigations confirmed that the CFCGRs in both $3.5 \% \mathrm{NaCl}$ and natural seawater were almost the same under free corrosion as 
well as under standard cathodic protection $(-0.8 \mathrm{~V})$, while they differed markedly under stronger protection of -1.0 V. Naturally, a biological activity effect would appear in prolonged tests in natural seawater only, but it is not considered in the present paper. The CFCGR characteristics for region I are satisfactorily described by Equation (1); that is, the relative effect of the environment ( $\beta$ ) is dependent on $a_{n}$ only, and this is independent of the mechanical properties and microstructure of weldable low carbon and low alloy steels (YS $=265-932 \mathrm{MPa})$ as well as independent of $\Delta K$, the specimen types and dimensions (including thickness), the stress ratio $(R=0-0.7)$, and the cycle frequencies $(f=0.00139-1 \mathrm{~Hz})$ [3].

The value of $\beta$ in region II is independent of the crack netlength $a_{n}$ but depends on $\Delta K$, the specimen thickness, and the loading frequency $f$. The following values of the constants $C_{I I}=214\left(\mathrm{MPa} \cdot \mathrm{m}^{1 / 2}\right)^{\mathrm{n}}$, or alternatively $\Delta K_{I I-I I}=87.5 \mathrm{MPa} \cdot \mathrm{m}^{1 / 2}$, and $n=1.2$ for region II have been evaluated in [3] for the frequency $f=0.1 \mathrm{~Hz}$. The value of $(\mathrm{d} a / \mathrm{d} N)_{e}$ in both regions is, naturally, dependent on $\Delta K$ and the stress ratio $R$ in the same way as $(\mathrm{d} a / \mathrm{d} N)_{a i r}$ is. For region II, the characteristics are not so satisfactorily described as for region I, since the effects of some variables are not recognized. The effects of the mechanical properties of steels are unknown, and although they cannot be excluded, they do not seem to be of primary importance. The effect of material thickness is evident [3]: an increase of the thickness from $7.5 \mathrm{~mm}$ to very large values (theoretically "infinite") causes an increase of CFCGR by a maximum of a factor of 1.4. The characteristics for region II are valid for a loading frequency of $0.1 \mathrm{~Hz}$ only (the effect of $f$ will be introduced below) and analogously to region I for any given stress ratio $R \geq 0$, since the effect of the R-value decreases as $\Delta K$ is increased.

The validity of the characteristics for both regions for $R<0$ has not been confirmed. However, the tests reported by Morgan and Thorpe [8] have shown that for $R=-1$, the FCGRs in air were close to the upper bound of the rates for $R \geq 0$, while CFCGRs were close to the lower bound of results for $R \geq 0$. This means that the relative effect of the environment ( $\beta$ ) for $R=-1$ is lower than for $R \geq 0$, that is, lower than is predicted by relation (1). An analogous conclusion can be drawn from the test results of Kostenko and Tetarencev [9]. Thus for $\mathrm{R}<0$, the characteristics for both regions represent a conservative estimation of CFCGR. For $R=-1$, the degree of this conservativeness does not seem to be significant but should be more significant for more negative $R$-values, since saltwater reacts with the crack tip only when the crack is opened.

The reason for the absence of the loading frequency effect in region I and its presence in region II has been explained on the basis of a theoretical model [6], but the model does not allow the effect to be described quantitatively. However, the effect of frequency cannot be considered negligible - it is of primary importance when taking into account a wide range of loading frequencies occurring in the service of ship and offshore structures. The saltwater temperature is another factor that should be included in empirical models and should be analysed against the background of the assumed division of the CFCGR diagrams into regions I and II. The main goal of the present paper is to elaborate some empirical characteristics that include both loading frequency and sea water temperature effects, which can be applied in corrosion fatigue crack propagation lifespan prediction for structural details. The possible ranges of the loading frequency exponent and activation energy values to be put into the characteristics have been proposed. For more tentative predictions, the characteristics do not need any other empirically evaluated constants besides the characteristics for FCGR, which can be found very easily in the literature. Other models [1] need numerous empirical constants even for a purely mechanical fatigue case.

\section{EFFECT OF LOADING FREQUENCY}

The effect of the loading frequency on the FCGR characteristics is usually considered negligible. For environments more aggressive than a standard atmosphere, the CFCGR characteristics should include the effect of loading frequency. Usually, this effect is taken into account only in region II of the characteristics, while in region I it is very weak or does not exist. The following form of the relation between CFCGR and the load cycle frequency $f$ is proposed:

$$
\frac{\mathrm{d} a}{\mathrm{~d} N} \propto f^{-k}
$$

In general, the loading-frequency effect has been evaluated below on the basis of published data. The authors of the published data investigated just the effect of the loading frequency but almost none of them evaluated the exponent $k$. The present author has not investigated the very same steel specimens under different frequencies of loading and under the very same remaining parameters characterizing the test conditions. However, the same St41U5 grade steel has been investigated under frequencies of $1 \mathrm{~Hz}$ using SEN specimens [10] and $0.1 \mathrm{~Hz}$ using CT specimens [11]. The crack growth rate characteristics for region II described by Equation (2) are independent of the crack net-length, and therefore the characteristics should be independent of the specimen type; thus the test results for region II for different specimen geometries can be compared directly. The same curve described by Equation (2) has been used as a reference one to evaluate the loading frequency effect for $15 \mathrm{G} 2 \mathrm{ANb}$ grade steel of a higher strength investigated by the present author [10] and even for a high-strength quenched and tempered steel investigated by Knight [12]. This approach could be a little risky, since the effect of steel strength on the region-II characteristics cannot be excluded, although it has not been evidently shown by any author. This effect of steel strength has been demonstrated for cathodic protected steels only [13].

The values of the exponent $k$ shown in Table 1 should be considered as approximate only. The ratios of the CFCGRs for different frequencies (e.g. $f_{2}$ and $f_{1}$; see Fig. 1) have been 
read from each diagram: one value at $\Delta K=\Delta K_{\mathrm{I}-\mathrm{II}}$ for the lower frequency $\left(f_{2}\right)$ and other value at $\Delta K>\Delta K_{\mathrm{I}-\mathrm{II}}\left(f_{2}\right)$. This means that the compared rates were from region II of the characteristics. For $\Delta K<\Delta K_{\mathrm{I}-\mathrm{II}}\left(f_{2}\right)$, the frequency effect would be underestimated since the rate for $f_{2}$ was from region I, which is independent of $f$, while for higher frequencies the rates were from region II.

The results for grade R5 steel obtained by Zhang et al. [14] need some comments. There are no distinguished regions I and II in [14]. The results were obtained under constant $\Delta K$ by "shedding the applied load range as crack length increased [...] and gradually decreasing the loading frequency (in steps of $1.0,0.5,0.1$ and $0.05 \mathrm{~Hz}$ ) [...] in $1 \mathrm{~mm}$ crack increments" per each level of frequency. Although the values of constants $\Delta K_{I I-I I I}$ and $n$ in Equation (1b) for region II are not as well verified by experiments $[3,30]$ as constants in (1b) for region I, they can be considered as tentative values. The corrosion fatigue crack growth rate for region II for R5 steel at $500 \mathrm{~N} /$ $\mathrm{mm}^{3 / 2}$, calculated by Equation (1) (correcting for a frequency of 0.2 not $0.1 \mathrm{~Hz}$ ) equals $1.75 \cdot 10^{-4} \mathrm{~mm} / \mathrm{c}$, while the rate read from the appropriate diagram (Fig. 2 in [14]) is about $1.66 \cdot 10^{-4}$ $\mathrm{mm} / \mathrm{c}$.

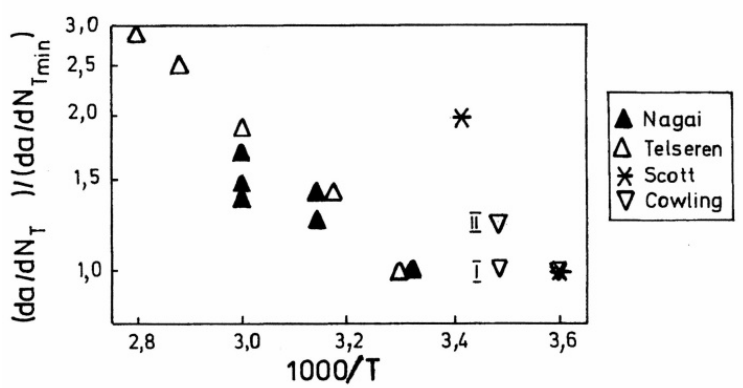

Fig.2. Arrhenius plot elaborated by the present author [30] for different test data $[7,17,28,29]$.

The data can, therefore, be attributed to region II, where the CFCGRs are independent of crack net-length and dependent on frequency. For $\Delta K=300 \mathrm{~N} / \mathrm{mm}^{3 / 2}$, however, the calculated rates for region II in R3, R4, and R5 grades of mooring steels, from two manufacturers each, are equal from 6.4 to $9.1 \cdot 10^{-5} \mathrm{~mm} / \mathrm{c}$, while the read-off values are between 1.3 and $2.3 \cdot 10^{-5}$ for a frequency of $0.2 \mathrm{~Hz}$ and below $3 \cdot 10^{-5} \mathrm{~mm} / \mathrm{c}$ for the lowest frequency tested. The data for $\Delta K=300 \mathrm{~N} / \mathrm{mm}^{3 / 2}$ can therefore be attributed to region I instead, where they should be independent of the loading frequency. Meanwhile, a frequency reduction from 1 to $0.05 \mathrm{~Hz}$ caused increases of the CFCGRs by factors of 1.15 to 1.50 . In the opinion of the present author, this could be caused by the crack length $\left(a_{n}\right)$ effect. Zhang et al. did not give information in [14] about the crack lengths corresponding to the frequencies of $1.0,0.5$, 0.1 , and $0.05 \mathrm{~Hz}$, but the present author deduced that the $a_{n}$-values were about 2.5 and $5.5 \mathrm{~mm}$ for frequencies of 1.0 and $0.05 \mathrm{~Hz}$, respectively. This means that the multiplication factor caused by the $a_{n}$-effect shown by Equation (1b) was 1.48 , thus in four cases out of six the factor is stronger than the (apparent, if the argumentation is valid) effect of frequency.
This phenomenon could be caused by: (i) a weaker effect of $a$ at such low value of $\Delta K$, since the effect was originally based on data gathered at higher $\Delta K$-values; (ii) an inverse frequency effect sometimes observed at low $\Delta K$; that is, "decreased frequency gave decreased crack growth rates, as well as an increased corrosion fatigue crack growth threshold" [15]. Under free corrosion conditions and at high $R$-values, the inverse frequency-effect could be caused by crack-tip blunting by anodic dissolution at low CFCGRs.

In synthetic soil solution, exponent $k$ is equal to 0.1 [16], whereas in seawater under a cathodic potential of $-1.05 \mathrm{~V}$ and in sour brine solution under free corrosion, the exponent increases from 0.28 to 0.67 as the steel strength is increased [15]. In saltwaters under free corrosion, the obtained values of exponent $k$ are contained in the broad range of $0.17-0.44$ (Table 1). In many cases where the values of exponent $k$ were evaluated for different values of $\Delta K$, for room and lower temperatures a more or less marked decrease of the exponent with an increase of $\Delta K$ is evident. This means that CFCGR curves obtained for different but constant loading frequencies (e.g. Fig.1) exhibit convergence in the increasing $\Delta K$ direction. At elevated temperatures the curves for different frequencies are parallel $(\mathrm{T}=320 \mathrm{~K})$ or they exhibit a divergence $(\mathrm{T}=345 \mathrm{~K})$. The CFCGR data for different frequencies and different temperatures have been obtained on the basis of Thomas and Wei's [23] test results simply as a sum of the "pure" CFCGR, read from appropriate diagrams in [23], and the mechanical FCGR equation (in this case in argon gas, not in air) taken from the same reference.

The arithmetic mean values of the exponent $k$ over some ranges of $\Delta K$ for each steel have been given in Table 1. Values of $k$ for any given $\Delta K$ differed from the mean value by a maximum of the order of $\pm 20 \%$ in eight cases and of the order of $10 \%$ or below for the remaining 11 cases (about $0 \%$ for SM41A, St41U5, 15G2ANb, HT55, Q1(N), 12Ni5Cr3Mo, Fe410, and Fe510). The values of $k$ are summarized in Table 2. It is evident that a stronger effect of the loading frequency (larger $k$-values) is observed for steels of yield strength (YS) below $500 \mathrm{MPa}$, where the arithmetic mean value of exponent $k$ is very similar to that resulting from the theoretical model [6]. The overwhelming majority of steels of this group have equilibrium ferritic-pearlitic microstructure, while the steels of YS > 500 MPa are quenched and tempered or thermomechanically processed.

The following formula for CFCGRs in region II is based on Formula (2) with $\Delta K_{I I-I I I}=87.5 \mathrm{MPa} \cdot \mathrm{m}^{1 / 2}=2766 \mathrm{~N} / \mathrm{mm}^{3 / 2}$ and $n=1.2$ evaluated for the loading frequency $f=0.1 \mathrm{~Hz}$ [9] and does not take into account the mentioned drop of $k$-values with an increase of $\Delta K$-values, assuming that $k$-values are averaged over some $\Delta K$ ranges:

$$
\frac{\mathrm{d} a}{\mathrm{~d} N_{f}}=\frac{\mathrm{d} a}{\mathrm{~d} N_{\text {air }}} \cdot 0,1^{k} f^{-k}\left(\frac{\Delta K}{\Delta K_{I-I I I}}\right)^{-n}
$$

The above formula with the abovementioned values of constants $\Delta K_{I I-I I I}$ and $n$ enables the prediction of all the region-II CFCGR diagrams obtained by the present author 
and by the other authors that are cited in [3]. The predicted rates differ from the measured ones by a maximum factor of 1.5 (usually lower), and therefore the formula gives a first approximation of the CFCGR characteristics for region II for all analysed steels. Different values of constants $\Delta K_{I I-I I I}$ and $n$ will, presumably, be determined in future on the basis of more numerous test results. The same formula (4) has been used to describe the results of Oberparleitner and Schutz [27] for steel grades FeE355KT (YS $\geq 355 \mathrm{MPa}$ ), FeE460 (YS $\geq 460 \mathrm{MPa}$ ), and FeE690 (YS $\geq 690 \mathrm{MPa}$ ) with a small error of about $10 \%$. The CFCGRs for FeE355KT steel were slightly overestimated while for both grades of higher strength the rates were slightly underestimated; this means that an increase of the steel strength caused only a slight increase of the CFCGRs under free corrosion potential. The independency of the exponent $k$ of $\Delta K$ is a simplification of the present empirical model that agrees with the present author's theoretical model [6].

\section{EFFECT OF THE WATER TEMPERATURE}

Relations (1), (2), and (4) are valid for a saltwater environment at room temperature only. The description and evaluation of the temperature effect shown below are based on the approach widely applied to the rate of the corrosion process, which is considered to be a thermally activated process. For CFCGRs, this approach was applied for the first time by Telseren and Doruk [28]. According to this approach, the CFCGR for any given temperature $T$, that is, $\mathrm{d} a / \mathrm{d} N_{T}$, can be expressed by the following proportion:

$$
\frac{\mathrm{d} a}{\mathrm{~d} N}{ }_{T} \propto \exp \left(\frac{-E_{a c t}}{R_{G} T}\right)
$$

where $E_{\text {act }}$ is the activation energy of the process, $T$ is the environmental temperature (in $\mathrm{K}$ ), and $R_{G}=8.3143 \mathrm{~J} \cdot \mathrm{K}^{-1} \cdot \mathrm{mole}^{-1}$ is the gas constant.

For data obtained by Thomas and Wei [23], the activation energy values $E_{a c t}$ have been calculated directly by Equation (5), that is, by comparison of the ratio of CFCGRs at two different temperatures to the ratio of the above exponential function values at the same temperatures. $E_{a c t}$ values are shown in Table 3 for different temperature intervals. In some cases, the real stress intensity factor $\Delta K$ levels corresponding to both of the compared temperatures differed more than in other cases. In these cases, the directly evaluated $E_{a c t}$ can be considered as apparent values. According to Equations (1) and (2), these values of $E_{a c t}$ have been corrected for the $\Delta K$ effect, assuming that the CFCGR is proportional to $(\Delta K)^{m}$ for region I and to $(\Delta K)^{m-n}$ for region II, with values of $n=1.2$ and Paris Law exponent $m=3.37$ (this last was evaluated by Thomas and Wei). The apparent and corrected values of $E_{\text {act }}$ are marked with single or double asterisks in Table 3.

The above relation (5) also means that the CFCGR expressed as a function of reciprocal temperature, that is, on the Arrhenius diagram, can be approximated by a straight line, and the activation energy can be evaluated on the basis of the slope of the line. In order to evaluate this energy, for the reanalysed investigations [7, 17, 28, 29], a ratio of the CFCGR at any given temperature $\left(\mathrm{d} a / \mathrm{d}_{T}\right)$ to the rate at the lowest temperature tested in the same investigations ( $\mathrm{d} a /$ $\mathrm{d}_{\text {Tmin }}$ ) has been calculated and plotted on the Arrheniustype diagram (Fig. 2) [30]. The values of activation energy are shown in Table 4.

It is difficult to draw general qualitative and quantitative conclusions concerning the effect of temperature because of the limited number of data. In fact, all investigations and theoretical analyses of weldable steels [7, 17, 23, 27, 28] have shown that in region II the temperature effect is undoubtedly present. In their theoretical model, Thomas and Wei [23] assumed no temperature effect at all in region $\mathrm{I}$, whilst assuming that there is an effect in region II. Matocha [31] tested a low alloy steel with a medium carbon content (sensitive to stress corrosion cracking SCC, and not weldable) in distilled water, and similarly stated that a strong effect of temperature exists only in region II of the CFCGR curves $\left(E_{\text {act }}=21.64 \mathrm{~kJ} / \mathrm{mole}\right)$. Regarding region I, however, there are some controversies:

- some researchers are of the opinion that the temperature effect does not exist in region I; that is, Thomas and Wei [23] showed this by a theoretical model and Matocha [31] did so based on the test results for a non-weldable steel;

- the test results of weldable steels obtained by Thomas and Wei [23] and Cowling et al. [29] have led the present author to a different opinion that the temperature effect in region I does not exist at low temperatures (below room temperature) but evidently exists at elevated temperatures (above room temperature).

The test results obtained by Scott and Silvester [7] are singular and need some comments. They stated that CFCGR decreased by a factor of two as the saltwater temperature decreased from 20 to $5{ }^{\circ} \mathrm{C}$. This leads to a very high activation energy value of $31.3 \mathrm{~kJ} / \mathrm{mole}$, as shown in Table 4 . This resulted directly from the comparison of two different series of data points for these temperatures (Fig. 3). The authors stated that the data in this figure had been gathered under the following load ranges: 0.9 to $13.3 \mathrm{kN}(\Delta \mathrm{P}=12.4 \mathrm{kN})$ and 0.9 to $17.8 \mathrm{kN}$ $(\Delta \mathrm{P}=16.9 \mathrm{kN})$. However, they did not define which data are for which level of $\Delta \mathrm{P}$. Taking into account the fact that in both series the specimen geometry (including notch depth) was the same and that the fatigue crack net-length (i.e., as measured from the notch root) at the beginning of the crack growth recording were similar, the above $\Delta \mathrm{P}$ values can be attributed to the definite series of data. The values of $\Delta K$ read from the diagrams for the initial (first from the left) data point are 15.2 and $19.7 \mathrm{MPam}^{1 / 2}$ for temperatures of 20 and $5^{\circ} \mathrm{C}$, respectively. Thus the ratio of the second value to the first is 1.3 , while the ratio of the higher to the lower value of $\Delta \mathrm{P}$ is 1.36 . Therefore it can be concluded that the experimental data for $5{ }^{\circ} \mathrm{C}$ have been obtained at $\Delta \mathrm{P}=16.9 \mathrm{kN}$ and the data for $20^{\circ} \mathrm{C}$ at $\Delta \mathrm{P}=12.4 \mathrm{kN}$. The true value of the temperature effect is, therefore, masked by the $\Delta P$ effect (Fig. 1) and the value $E_{\text {act }}=31.3 \mathrm{~kJ} /$ mole can be considered 
as an apparent value (see Table 4). A more realistic value can be determined by comparison of the data for $5{ }^{\circ} \mathrm{C}$ (obtained for $\Delta \mathrm{P}=16.9 \mathrm{kN}$ ) with the curve for $20^{\circ} \mathrm{C}$ for the same $\Delta \mathrm{P}$; the last curve has been predicted by Equation (1). This value is marked in Table 4 as a corrected value. Scott and Silvester have not given detailed information about the specimen type and geometry (only the thickness $\mathrm{B}=25.4 \mathrm{~mm}$ ). In his letter to the present author (from the year 1991), P.M. Scott also stated that the specimens used were CT-type of width $\mathrm{W}=50.8 \mathrm{~mm}$, but he did not provide information on the notch depth $a_{\text {notch }}$, which is necessary to calculate the crack net-length $a_{n}$. By entering the abovementioned initial values of $\Delta \mathrm{K}$ and the abovementioned values of $\mathrm{B}, \mathrm{W}$, and $\Delta \mathrm{P}$ into the formula most commonly used in the seventies of the 20th century for the stress intensity factor [32], one can obtain initial $a / W$ values equal to 0.382 and 0.375 for 20 and $5{ }^{\circ} \mathrm{C}$ respectively. The most probable value of $a_{\text {notch }} / W$ is 0.3 since: (i) the formula for the stress intensity factor is valid for $a / W$ $\geq 0.3$; and (ii) the initial values of $a_{n}$ are then equal to 4.16 and $3.78 \mathrm{~mm}$ for temperatures of 20 and $5{ }^{\circ} \mathrm{C}$, respectively, that is, very close to very often applied pre-crack lengths $\left(a_{n}\right)$.

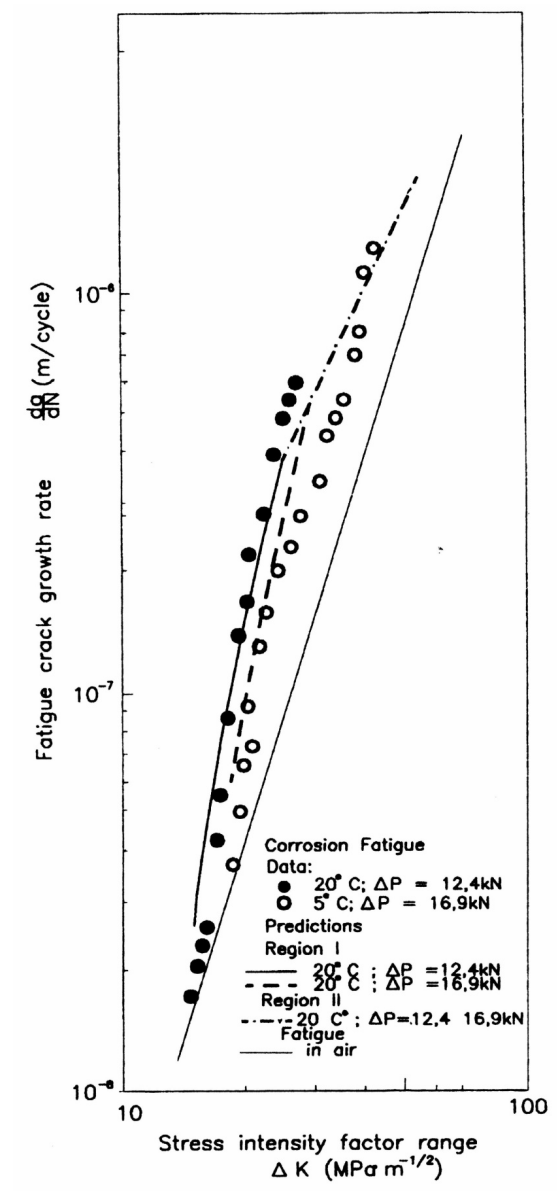

Fig.3. Comparison of the crack growth rates for different temperatures [7] and the prediction considering the effect of the different load ranges (indication of the long crack length effect), at a loading frequency equal to $0.1 \mathrm{~Hz}$, and oxygen content in the range $7-8 \mathrm{mg} / \mathrm{l}$.

The predicted curves for $20^{\circ} \mathrm{C}$ for both $\Delta \mathrm{P}$ levels are shown in Fig. 3. The good fit of the experimental data to the predicted curve for the same $\Delta \mathrm{P}$ of $12.4 \mathrm{kN}$ is an additional confirmation of the validity of the empirical model described by Equation (1) and less precisely by Equation (2). Comparing the data for $5{ }^{\circ} \mathrm{C}$ to the predicted curve for the same $\Delta \mathrm{P}$-level but a temperature of $20^{\circ} \mathrm{C}$, it is evident that over a dominant part of region I the CFCGRs are approximately independent of the temperature shift from 20 to $5{ }^{\circ} \mathrm{C}$. A temperature effect is observed only for values of $\Delta \mathrm{K}$ above about $29 \mathrm{MPa} \cdot \mathrm{m}^{1 / 2}$, close to the border between regions I and II and in region II. Values of $E_{\text {act }}$ equal to about 24, 17.6, and $14.3 \mathrm{~kJ} / \mathrm{mole}$ have been determined in this area of the diagram for values of $\Delta K$ of about $29,32.5$, and $35.3 \mathrm{MPa} \cdot \mathrm{m}^{1 / 2}$, respectively; the mean value of $E_{a c t}$ is equal to $18.6 \mathrm{~kJ} / \mathrm{mole}$. It is worse recalling Thomas and Wei's [23] results, for which the average value $E_{\text {act }}$ has been assumed to be $0 \mathrm{~kJ} /$ mole (Table 3 ) in region I below room temperature. For the highest value of $\Delta \mathrm{K}$ (about $31 \mathrm{MPa} \cdot \mathrm{m}^{1 / 2}$ ), close to the border between regions I and II in [23], values of $E_{\text {act }}$ were evidently greater than zero (Table 3 ). The averaged value of $18.6 \mathrm{~kJ} / \mathrm{mole}$, which is based on Scott and Silvester's [7] results, can be considered as representing region II rather than region I. Thus it seems that Scott and Silvester's data for low temperatures support rather the above expressed opinion (2) regarding the lack of the temperature effect in region I for temperatures below room temperature.

CFCGR in a water environment of any given temperature $\mathrm{T}$ can be evaluated by the following equation resulting from Equation (5):

$$
\frac{\mathrm{d} a}{\mathrm{~d} N_{T}}=\frac{\mathrm{d} a}{\mathrm{~d} N_{T_{r}}} \cdot \exp \left(\frac{E_{a c t}\left(T-T_{r}\right)}{R_{G} T_{r} T}\right)
$$

where $T_{r}$ is room temperature and $\mathrm{d} a / \mathrm{dN}_{T r}$ is the CFCGR at the room temperature. In spite of the limited number of data available and the large variance of the activation energy $\left(E_{a c t}\right)$, the present author suggests the following tentative values of $E_{\text {act }}$ to be entered in the above equation: $9-18.6 \mathrm{~kJ} /$ mole in region II and in region I close to the border with region II for low and elevated temperatures, $0 \mathrm{~kJ} / \mathrm{mole}$ in region $\mathrm{I}$ for $\mathrm{T} \leq T_{r}$, and $9 \mathrm{~kJ} / \mathrm{mole}$ in region $\mathrm{I}$ for $T \geq T_{r}$; this last value is based on Thomas and Wei's [23] data only. For more precise calculations, appropriate values of $E_{\text {act }}$ should be determined on the basis of the test results of the analysed material, environment (including temperature interval), and loading parameters.

According to the out-of-date Polish Standard PN-79/H-04370 for impact tests, the term "room temperature" in the present paper is defined as the temperature in the range of ${ }^{\circ} \mathrm{C}$, which is broader than that in the current standard PN-EN 10045-1, where it is defined as $23 \pm 5^{\circ} \mathrm{C}$.

\section{JOINT EFFECT OF THE LOADING FREQUENCY AND WATER ENVIRONMENT TEMPERATURE AND ITS VERIFICATION}

Since equations (1), (2), and (4) have been obtained and verified for saltwater environments at room temperature, the term $\mathrm{d} a / \mathrm{dN}_{\mathrm{Tr}}$ in Equation (6) has been substituted by the crack 
growth rate given by Equations (1) and (4). The following final formulae for CFCGR at any given loading frequency $f$ and saltwater temperature $T$ have been obtained:

for region I

$$
\frac{\mathrm{d} a}{\mathrm{~d} N}_{f T}=\frac{\mathrm{d} a}{\mathrm{~d} N}_{\text {air }} \cdot 1.15\left(a_{n}\right)^{1 / 2} \cdot \exp \left(\frac{E_{a c t}\left(T-T_{r}\right)}{R_{G} T_{r} T}\right)
$$

for region II

$$
\frac{\mathrm{d} a}{\mathrm{~d} N_{f T}}=\frac{\mathrm{d} a}{\mathrm{~d} N_{\text {air }}} \cdot 0,1^{k} f^{-k}\left(\frac{\Delta K}{\Delta K_{I I-I I I}}\right)^{-n} \cdot \exp \left(\frac{E_{a c t}\left(T-T_{r}\right)}{R_{G} T_{r} T}\right)
$$

where $a_{n}$ is in millimetres. The values of the constants $\Delta K_{I I-}$ ${ }_{I I I}=87.5 \mathrm{MPa} \cdot \mathrm{m}^{1 / 2}=2766 \mathrm{~N} / \mathrm{mm}^{3 / 2}$ and $n=1.2$ for region II have been verified on the basis of a smaller number of experimental data than the coefficient 1.15 and the exponent $1 / 2$ in Equation (7).

The frequency or temperature effects have been evaluated based on the measured distances between different CFCGR curves in appropriate published diagrams. The curves have usually been given by relatively large data points with scatter in log-log coordinates, not by approximation lines. The present author assessed that individual values of exponent $k$ and energy $E_{\text {act }}$ differed from their mean values due to inaccurate readouts from diagrams by a maximum of about $\pm 5 \%$. In the case of $E_{a c t}$, larger error is due to scatter of CFCGRs. The accuracy for mean values is better and depends on a number of individual measurements. The above model with proposed values of parameters has been elaborated not to substitute for empirical data for specific materials in specific conditions but rather to be used when there are no data and a tentative approach is acceptable.

Below, the CFCGRs predicted by the above formulae (7) and (8) have been compared with the total values of CFCGRs calculated by the present author on the basis of the experimental results obtained by Thomas and Wei [23] for different values of loading frequency and different values of saltwater temperature. Their tests were realized under $\Delta K$ = constant, with the loading frequency abruptly changing as the crack length increased in the range of 9-18 mm according to an appropriate diagram given in [23]. Mechanical FCGRs, $\mathrm{d} a / \mathrm{d} N_{m}$, were tested in argon gas, and therefore $\mathrm{d} a / \mathrm{d} N_{m}$ has been substituted for $\mathrm{d} a / \mathrm{d} N_{a i r}$ in Equations (7) and (8). The average value of exponent $k$ of 0.24 for high-strength steels has been assumed. Values of $E_{\text {act }}$ based on [23] are differentiated largely over the tested ranges of $\Delta K, T$, and $f$ (Table 3 ); the present author has not been able to find any regularity in this differentiation, and therefore some averaged values have been assumed: $9 \mathrm{~kJ} / \mathrm{mole}$ for region I at elevated temperatures and for region II for all temperatures tested and $0 \mathrm{~J} / \mathrm{mole}$ for region I below room temperature.

The comparison of the experimental results data with the predictions is shown in Figures 4 and 5 for $\mathrm{T} \leq \mathrm{T}_{\mathrm{r}}$ and $\mathrm{T}>\mathrm{T}_{\mathrm{r}}$ respectively. Conformity of the predictions with the data seems to be satisfactory in spite of the use of averaged values of $E_{\text {act }}$. For the highest $\Delta K \approx 30 \mathrm{MPa}$, at all the temperatures tested, the tests practically run in the region II regime only, since the crack lengths were relatively long $\left(a_{n}=9-18 \mathrm{~mm}\right)$. The predictions for region I are not represented by straight horizontal lines as could be expected, since the tests at every frequency of loading were realized in another crack length interval, so the crack length effect appeared for the long cracks. The crack length effect for such long cracks is not as appreciable as for $a_{n}<9 \mathrm{~mm}$, but comparison of the prediction to the data points suggests that the effect could be partially responsible for variations of the CFCGRs for different frequencies of loading in region $\mathrm{I}$, where a pure effect of frequency should not exist.
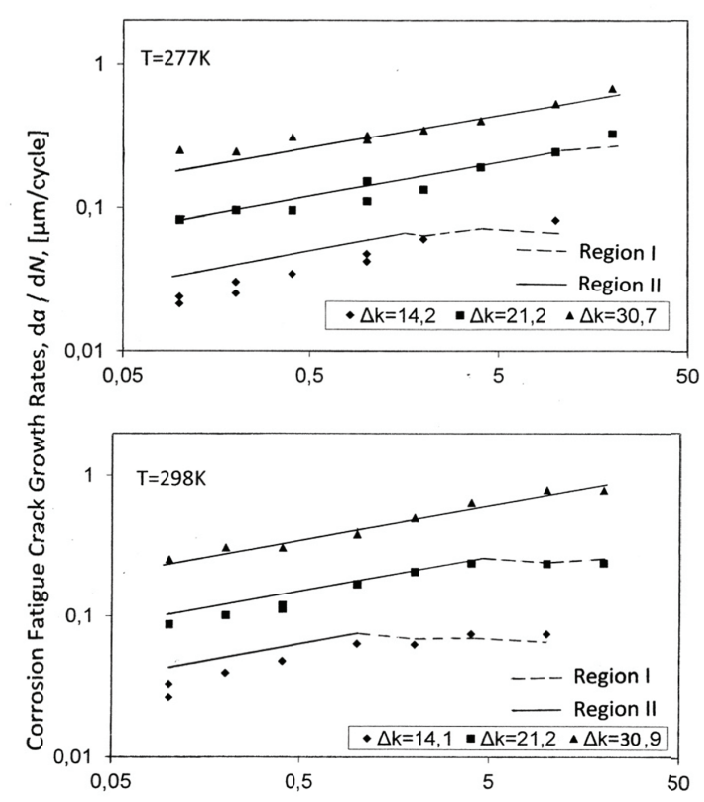

Loading Cycle Period, 1/frequency, [s]

Fig.4. Comparison of the corrosion fatigue crack growth rates in HY 130 steel at room and a lower temperatures, calculated by the present author on the basis of the results obtained by Thomas and Wei [23] (points), with the rates predicted by equations (8) and (9) (curves) for the different values of stress intensity factor range $\Delta K[\mathrm{MPa} \sqrt{\mathrm{m}}]$ and loading frequency.

Contrary to all other tests realized under free corrosion potential and discussed in the present paper, Thomas and Wei's tests [23] were realized under cathodic potential, although the degree of the cathodic polarization does not seem to be very strong, since the cathodic potential was only $0.036 \mathrm{~V}$ below the free corrosion potential. A reanalysis of Scott and Silvester's [7] data has revealed that a load-range effect qualitatively similar to that observed under free corrosion potential (Fig.1), but somewhat weaker, has also appeared at a potential of $-0.8 \mathrm{~V}$, that is, about $0.15 \mathrm{~V}$ below the free corrosion potential. This effect, although still weaker, appears even at a potential of $-1 \mathrm{~V}$ but in low-oxygen water only, while in well-oxygenated water the effect disappears. This load range effect has previously been recognized as an indication of the long-crack-length effect. This effect exhibits a tendency to disappear at higher stress intensity factor levels, 
analogously to the effect for free corrosion conditions. For the highest stress intensities, the CFCGRs under the cathodic potential are almost independent of the load range $(\Delta P)$ and at $-0.8 \mathrm{~V}$ they are approximately equal to the rates predicted for region II by Equations (2) or (7) for free corrosion potential. The abovementioned similarities of the CFCGR's behaviour under free corrosion and a cathodic potential of $-0.8 \mathrm{~V}$, as well as the successful approximation of Thomas and Wei's [23] results by Equations (6) and (7) developed for free corrosion potential (Figs. 4 and 5), account for consideration of Thomas and Wei's test results together with data from the remaining tests that were obtained under free corrosion conditions.

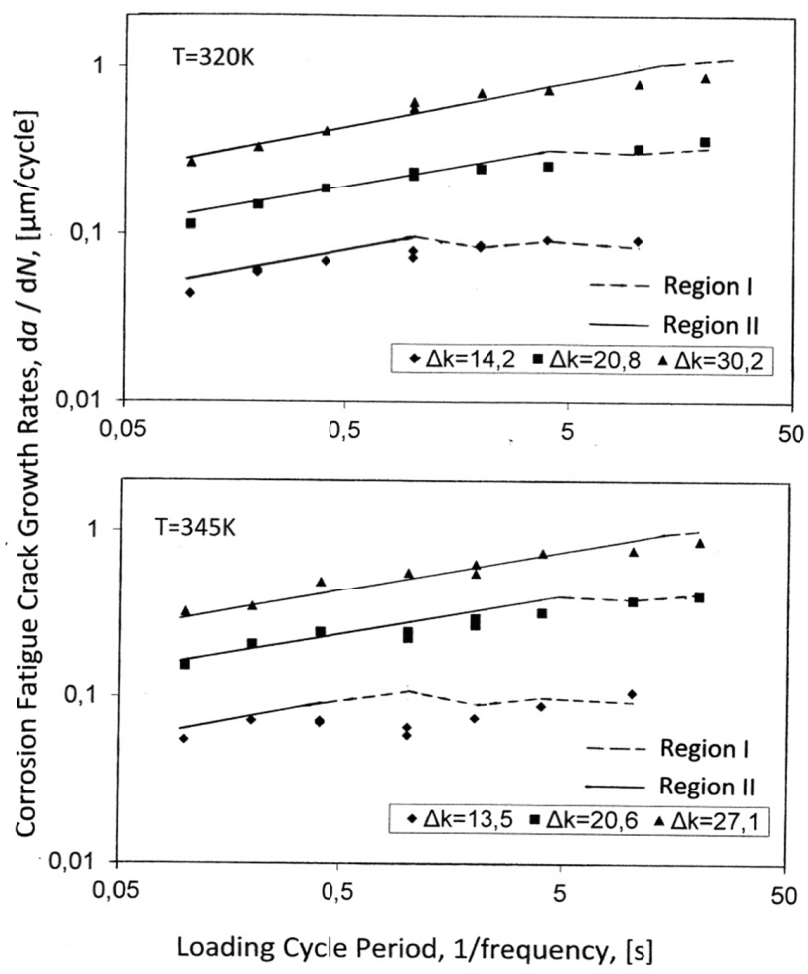

Fig.5. Comparison of the corrosion fatigue crack growth rates for HY 130 steel at some elevated temperatures, calculated by the present author on the basis of results obtained by Thomas and Wei [23] (points), with the rates predicted by equations (8) and (9) (curves) for the different values of the stress intensity factor range $\Delta K[\mathrm{MPa} \sqrt{\mathrm{m}}]$ and loading frequency.

\section{CONCLUSIONS}

The corrosion fatigue crack growth rate (CFCGR) characteristic for long cracks has been divided into three regions: region $\mathrm{I}$, with lower values of the stress intensity factor range $(\Delta K)$ and the crack net-lengths $\left(a_{n}\right.$, i.e. as measured from the notch root), and region II with higher values of $\Delta K$ and $a_{n}$. The characteristic has been described by the following equations:

for region I

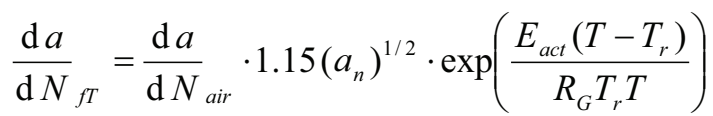

for region II

$$
\frac{\mathrm{d} a}{\mathrm{~d} N_{f T}}=\frac{\mathrm{d} a}{\mathrm{~d} N_{\text {air }}} \cdot 0,1^{k} f^{-k}\left(\frac{\Delta K}{\Delta K_{I I-I I I}}\right)^{-n} \cdot \exp \left(\frac{E_{a c t}\left(T-T_{r}\right)}{R_{G} T_{r} T}\right)
$$

where $\mathrm{d} a / \mathrm{d} N_{f T}$ is the CFCGR for any given frequency $(f)$ and temperature (T); $\mathrm{d} a / \mathrm{dN}_{\text {air }}$ is the mechanical FCGR (in air); $E_{\text {act }}$ is activation energy; $T$ and $T_{r}$ are the actual and room temperatures in a saltwater environment, respectively; $R_{G}$ is the gas constant; $n$ and $\Delta K_{I I-I I I}$ are constants, assumed to be equal to 1.2 and $87.5 \mathrm{MPa} \cdot \mathrm{m}^{1 / 2}$ respectively for numerous analysed tests; and $k$ is the exponent of the loading frequency $(f)$ effect. For region III, the CFCGR characteristics equal to FCGR ones are assumed. Assuming the evaluated (conclusions 2 and 3) averaged values of the exponent $k$ and the activation energy $E_{a c t}$, the only constants needed for a tentative prediction of CFCGR are the parameters of the mechanical FCGR characteristics.

The loading-frequency-effect exponent $k$ for numerous steels and different $\Delta K$-values varied in the broad range of 0.17 to 0.44 . In most of the cases where the values of $k$ were evaluated for different values of $\Delta K$ at room temperature, a more or less marked decrease of $k$ with increasing $\Delta K$ is evident. This means that CFCGR curves obtained for different but constant loading frequencies exhibit convergence in the direction of increasing $\Delta K$. Comparing averaged $k$-values for each steel, it is evident that a stronger effect of the loading frequency (larger $k$-values) is observed for steels of yield strength (YS) below $500 \mathrm{MPa}(k=0.33)$ than for YS $>500 \mathrm{MPa}$ $(\mathrm{k}=0.244)$.

The activation energy $\left(E_{a c t}\right)$ is a measure of the saltwater temperature effect. Although the number of available test results is poor, the following conclusions have been drawn: the effect is negligible in region I below room temperature, but is evident in the same region above room temperature and in region II at both low and elevated temperatures. Some tentative values of $E_{\text {act }}$ to be entered in the above equation have been suggested in the present paper. For more precise calculations, appropriate values $E_{\text {act }}$ should be determined on the basis of experiments for the analysed case.

A reanalysis of Scott and Silvester's comprehensive test results has shown that under a potential of $-0.8 \mathrm{~V}(0.15 \mathrm{~V}$ below the free corrosion potential), a long-crack-length effect exists that is qualitatively similar to the effect for free corrosion conditions.

\section{REFERENCES}

1. Vázquez J., Navarro C., Dominguez J. (2009). On the estimation of fatigue life in notches differentiating the phases of crack initiation and propagation. Fatigue Fract. Engng Mater. Struct., 33, 22-36.

2. Vosikovsky O. (1975). Fatigue crack growth in an X65 line pipe steel at low cyclic frequencies in aqueous 
environments, J. Engineering Materials and Technology, 97, 298304.

3. Jakubowski M. (1993). Geometry factors in corrosion fatigue crack propagation. Fatigue Fract. Engng Mater. Struct, 16, 495507.

4. Miller K.J. (1982) The short crack problem. Fatigue Engng Mater, Struct, 5, 223-232.

5. Lankford J. (1982) The growth of small fatigue cracks in 7075 aluminium. Fatigue Engng Mater. Struct, 5, 233-248.

6. Jakubowski M. (2007). A model of corrosion fatigue crack growth in ship and offshore steels. Fatigue Fract. Engng Mater. Struct., 30, 682-688.

7. Scott P. M., Silvester D. R. V. (1975). The influence of seawater on fatigue crack propagation in structural steel. Department of Energy, UK OSRP Technical Report 3/03.

8. Morgan H. G., Thorpe T. W. (1981). An introduction to crack growth testing in the UK OSRP and its relevance to the design of offshore structures. Proc. Fatigue in Offshore Structures, Thomas Telford Ltd, London,pp.515.

9. Kostienko N. A., Tatariencew W. A. (1987). Influence of overloading, stress ratio and moisture on fatigue cracks propagation resistance of cast steels. Fiz. Khim. Mekh. Mater., 23, No.2, 84-89 (in Russian).

10. Jakubowski M. (1982). Influence of saltwater on fatigue crack growth rates in shipbuilding steels. Zeszyty Naukowe PG, No.344, 121130 (in Polish).

11. Jakubowski M. (1986). A study crack length effect on the fatigue crack growth rate for ordinary shipbuilding steel in saltwater. $5^{\text {th }}$ Intl Symp. Offshore Mechanics and Arctic Engineering, Tokyo, ASME Book No. 100194, 212217.

12. Knight J. W. (1977). Corrosion fatigue of welded, quenched and tempered steels, Welding Research International, 7, 1738.

13. Jakubowski M. (1993). Fatigue and corrosion fatigue crack propagation rates for two new shipbuilding steels. Marine Technology Transactions, 4, 7384 (in Polish).

14. Zhang Y-H., Zettlemoyer N., Tubby P.J. (2012). Fatigue crack growth rates of mooring chain steels. Proc. ASME $201231^{\text {st }}$ Intl Conf. Ocean, Offshore and Arctic Engineering, OMAE2012-84223, pp. 1-10.

15. Hudak Jr.,S.J., Feiger J.H., Patton J.A.,(2010) The effect of loading frequency on corrosion-fatigue crack growth in high strength riser materials. Proc. ASME 2010 29th
Intl Conf. Ocean, Offshore and Arctic Engineering, OMAE2010-20705, pp.1-10.

16. Marvasti M,H., Chen W., Kania R., Worthingham R. and Van Boven G. (2010) Frequency dependence of fatigue and corrosion fatigue crack growth rate. Proc. $8^{\text {th }}$ Int. Pipeline Conference, IPC2010-31007, 1-7.

17. Nagai K., Iwata M., Yaima H., Yamamoto Y., Fujimoto Y. (1976). Effect of cycle frequency, mean stress, temperature and cathodic protection on fatigue crack growth in $3 \%$ salt-water. J. Society of Naval Architects Japan, 140, 255261.

18. Nibbering J. J. W. (1983). Behaviour of mild steel under very low frequency loading in sea water. Corrosion Science,.23, 645662 .

19. Scott P. M., Thorpe T. W., Silvester D. R. V. (1983). Rate determining process for corrosion fatigue crack growth in ferritic steels in seawater. Corrosion Science, 23, 559575.

20. Horstmann M., Gregory J. K., Schwalbe K.-H. (1995). Geometry effects on corrosion fatigue in offshore structural steels. Int. J. Fatigue, 17, 293299.

21. Endo K., Komai K., Matsuoda Y. (1981). Mechanical effects of corrosion products in corrosion fatigue crack growth of a steel, Bulletin of the Japan Society of Mechanical Engineering, 24, 13191325.

22. Gallagher J. P. (1971). Corrosion fatigue crack growth rate behavior above and below $K_{I S C C}$ in steels. J. of Materials, 6, 941964 .

23. Thomas J. P., Wei R. P. (1992). Corrosion fatigue crack growth of steel in aqueous solutions, I: Experimental results and modelling the effects of frequency and temperature. Materials Science and Engineering, A159, 205221.

24. Vosikovsky O. (1978). Frequency, stress ratio and potential effects on fatigue crack growth in HY130 steel in salt water, J. Testing and Evaluation, 1978, 6, ss.175182.

25. Barsom J. M. (1971). Mechanism of corrosion fatigue below $\mathrm{K}_{\mathrm{ISCC}}$. Int. J. of Fracture Mechanics, 7, 165-182.

26. Barsom J. M. (1971). Corrosion fatigue crack propagation

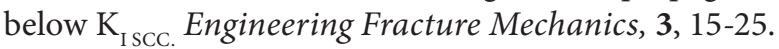

27. Oberparleitner W., Schutz W. (1988). Calculation of crack growth in welded specimens under seawater conditions in order to predict fatigue life of offshore components. Werkstoffe und Korrosion, 39, 369-378, (in German). 
28. Telseren A., Doruk M. (1974). Temperature dependence of water enhanced fatigue crack growth in mild steel. Engineering Fracture Mechanics, 6, 283

29. Cowling M. J., Hancock J. W., Appleton R. J., Gall D. S. (1985). Fatigue crack growth in biologically active environments under realistic load sequences, Glasgow University, Project OT/F/918 Final Report

30. Jakubowski M. (2002). Some problems of corrosion fatigue crack propagation in ship and offshore steels. Monographic Series, No 32, Gdansk University of Technology, 2002 (in Polish).

31. Matocha K. (2001). The influence of water environment on fatigue crack growth behaviour of high strength low alloy steel. XVI Physical Metallurgy and Materials Conference „Advanced Materials \& Technologies”, Gdañsk-Jurata, Poland, Inzynieria Materialowa, 4/2001, 617-619.

32. Wnuk M.P. (1973). Fundamentals of fracture mechanics. Skrypt No 822 AGH Krakow (in Polish) 
Table 1. The approximate values of the loading-frequency-effect exponent $(k)$ evaluated on the basis of different investigations at room temperature (exceptions are marked).

\begin{tabular}{|c|c|c|c|c|c|c|c|}
\hline Steel grade & $\begin{array}{c}Y S \\
M P a\end{array}$ & $\begin{array}{l}\text { UTS } \\
\text { MPa }\end{array}$ & $\underset{\mathrm{Hz}}{\text { range of } f}$ & $\underset{\mathrm{MPa} \sqrt{\mathrm{m}}}{\mathrm{DK}}$ & $k$ & average $k$ & ref. \\
\hline SM41A & 265 & 421 & $0.05-5$ & undefined & 0.31 & 0.31 & 17 \\
\hline St41U5 & 318 & 456 & $0.1-1$ & region II & 0.31 & 0.29 & 10 \\
\hline $15 \mathrm{G} 2 \mathrm{ANb}$ & 405 & 532 & $0.1-1$ & region II & 0.29 & 0.29 & 10 \\
\hline $\mathrm{Fe} 410$ & 313 & 492 & $0.0003-0.05$ & $\begin{array}{l}48 \\
64 \\
\end{array}$ & $\begin{array}{l}0.36 \\
0.33 \\
\end{array}$ & 0.345 & 18 \\
\hline $\mathrm{Fe} 510$ & 401 & 556 & $0.0017-0.1$ & $\begin{array}{l}46 \\
71\end{array}$ & $\begin{array}{l}0.33 \\
0.29\end{array}$ & 0.31 & 18 \\
\hline $\begin{array}{l}4360-50 \mathrm{D} \\
(\text { for } R<0,2 \text { ) }\end{array}$ & 370 & 540 & $\begin{array}{l}0.1-10 \\
0.1-1\end{array}$ & $\begin{array}{l}30 \\
50\end{array}$ & $\begin{array}{l}0.37 \\
0.24 \\
\end{array}$ & 0.305 & 19 \\
\hline $\begin{array}{l}4360-50 \mathrm{D} \\
(\text { for } R=0,5)\end{array}$ & 370 & 540 & $\begin{array}{l}0.01-1 \\
0.01-1\end{array}$ & $\begin{array}{l}12 \\
14,5\end{array}$ & $\begin{array}{l}0.41 \\
0.31 \\
\end{array}$ & 0.36 & 19 \\
\hline TStE355 & 380 & 530 & $0.008-0.5$ & $\begin{array}{l}20 \\
30 \\
40\end{array}$ & $\begin{array}{l}0.44 \\
0.38 \\
0.27\end{array}$ & 0.37 & 20 \\
\hline HT55 & 420 & 580 & $0.01-5$ & undefined & 0.36 & 0.36 & 21 \\
\hline X65 & 458 & 570 & $\begin{array}{l}0.01-1 \\
0.01-0.1 \\
\end{array}$ & $\begin{array}{l}35 \\
50 \\
\end{array}$ & $\begin{array}{l}0.37 \\
0.27 \\
\end{array}$ & 0.32 & 2 \\
\hline HY80 & 550 & - & $\begin{array}{l}0.01-1 \\
0.01-1 \\
0.01-0.1\end{array}$ & $\begin{array}{l}41 \\
82 \\
82 \\
\end{array}$ & $\begin{array}{l}0.21 \\
0.17 \\
0.26\end{array}$ & 0.22 & 22 \\
\hline $\mathrm{Q} 1(\mathrm{~N})$ & 619 & 730 & $0.00139-0.1$ & region II & 0.225 & 0.225 & 12 \\
\hline EStE690VA & 750 & 850 & $0.008-10$ & 23 & 0.28 & 0.28 & 20 \\
\hline R5 mooring chain steel & 797 & 1044 & $0.01-1$ & 15.8 & 0.257 & 0.257 & 14 \\
\hline HY130 & 932 & 974 & $\begin{array}{l}0.50-10.0 \\
0.25-10.0 \\
0.01-10.0\end{array}$ & $\begin{array}{l}14.1 \\
21 \\
30,9\end{array}$ & $\begin{array}{l}0.275 \\
0,269 \\
0,205\end{array}$ & 0.25 & 23 \\
\hline $\begin{array}{l}\mathrm{HY} 130 \\
\mathrm{~T}=277 \mathrm{~K}\end{array}$ & 932 & 974 & $\begin{array}{l}0.10-10.0 \\
0.05-10.0 \\
0.05-10.0\end{array}$ & $\begin{array}{l}14.2 \\
21.2 \\
30.7 \\
\end{array}$ & $\begin{array}{l}0.30 \\
0.27 \\
0.20 \\
\end{array}$ & 0.26 & 23 \\
\hline $\begin{array}{l}\mathrm{HY} 130 \\
\mathrm{~T}=345 \mathrm{~K}\end{array}$ & 932 & 974 & $\begin{array}{l}1.0-10.0 \\
0.10-10.0 \\
0.05-10.0\end{array}$ & $\begin{array}{l}13.1 \\
20.6 \\
27.1\end{array}$ & $\begin{array}{l}0.19 \\
0.22 \\
0.29\end{array}$ & 0.24 & 23 \\
\hline HY130 & 993 & 1034 & $0.01-1$ & $\begin{array}{l}30 \\
80\end{array}$ & $\begin{array}{l}0.23 \\
0.21 \\
\end{array}$ & 0.22 & 24 \\
\hline $12 \mathrm{Ni} 5 \mathrm{Cr} 3 \mathrm{Mo}$ & 1288 & 1309 & $0.1-10$ & any & 0.225 & 0.225 & 25,26 \\
\hline
\end{tabular}

Table 2. The averaged values of the loading-frequency-effect exponent ( $k$ ) for different groups of steels

\begin{tabular}{|l|l|l|}
\hline \multicolumn{1}{|c|}{ Yield Strength, YS, MPa } & \multicolumn{1}{|c|}{ averaging $\boldsymbol{k}$ for each steel } & \multicolumn{1}{|c|}{ average $\boldsymbol{k}$ for all steels } \\
\hline$Y S<500$ & $0.29-0.37$ & 0.33 \\
\hline$Y S>500$ & $0.22-0.28$ & 0.24 \\
& $0.22-0.30^{*}$ & $0.25^{*}$ \\
\hline$* /$ including values for elevated temperatures
\end{tabular}


Table 3. The values of activation energy $\left(E_{\text {ac }}\right)$ in [kJ/mole], evaluated on the basis of Thomas and Wei test results [23]. In the case of the stress intensity factor range $\Delta K$, the upper and lower located numbers in each cell represent values applied for the tests realised at the upper and lower temperature limits of the temperature interval, respectively.

\begin{tabular}{|c|c|c|c|c|c|c|c|c|c|}
\hline $\mathbf{T}[\mathrm{K}]$ & \multicolumn{3}{|c|}{$277-298$} & \multicolumn{3}{|c|}{$298-320$} & \multicolumn{3}{|c|}{$320-345$} \\
\hline$\Delta K \mathrm{MPam}^{1 / 2}$ & $\begin{array}{l}14.1 \\
14.2\end{array}$ & $\begin{array}{l}20.9 \\
21.2\end{array}$ & $\begin{array}{l}30.9 \\
30.7\end{array}$ & $\begin{array}{l}14.2 \\
14.1\end{array}$ & $\begin{array}{l}20.8 \\
20.9\end{array}$ & $\begin{array}{l}30.2 \\
30.9\end{array}$ & $\begin{array}{l}13.5 \\
14.2\end{array}$ & $\begin{array}{l}20.6 \\
20.8\end{array}$ & $\begin{array}{l}27.1 \\
30.2\end{array}$ \\
\hline \multicolumn{3}{|c|}{$\begin{array}{c}\mathbf{1 H z} \\
11.5 \\
8.6\end{array}$} & 7.3 & 6.6 & 11.4 & $\begin{array}{c}15.7 /^{*} \\
17.6 /^{* *}\end{array}$ & $\begin{array}{l}-6.4 /^{*} \\
-2.7 / * *\end{array}$ & 0 & $\begin{array}{l}-2.3 /^{*} \\
6.4 /^{* *}\end{array}$ \\
\hline $0.1 \mathrm{~Hz}$ & -2.4 & -1.0 & 11.2 & 8.0 & 10.9 & $\begin{array}{c}1.1 /^{*} \\
4.2 /^{* *}\end{array}$ & $\begin{array}{c}4.5 /^{*} \\
10.7 /^{* *}\end{array}$ & 4.5 & $\begin{array}{l}-1.5 /^{*} \\
11.8 /^{* *}\end{array}$ \\
\hline $0.05 \mathrm{~Hz}$ & - & -10.3 & 3.7 & - & 13.4 & $\begin{array}{l}4.7 /{ }^{*} \\
7.7 /^{* *}\end{array}$ & - & 2.8 & $\begin{array}{c}0 /^{*} \\
13.3 /^{* *}\end{array}$ \\
\hline \multicolumn{10}{|c|}{ The averaged activation energy $E_{a c t}[\mathrm{~kJ} / \mathrm{mol}]$} \\
\hline $\begin{array}{c}\text { Reg. I } \\
0.1 \& 0.05 \\
\mathrm{~Hz}\end{array}$ & \multicolumn{3}{|c|}{0.2} & \multicolumn{3}{|c|}{$8.8 /^{* *}$} & \multicolumn{3}{|c|}{$8.7 / * *$} \\
\hline $\begin{array}{l}\text { Reg. II } \\
1 \& 5 \mathrm{~Hz}\end{array}$ & \multicolumn{3}{|c|}{8.2} & \multicolumn{3}{|c|}{$11.7 /^{* *}$} & \multicolumn{3}{|c|}{$4.4 /^{* *}$} \\
\hline $\begin{array}{l}* / \text { apparent } \\
* * / \text { value corr }\end{array}$ & . & & & & & & & & \\
\hline
\end{tabular}

Table 4. The activation energy $\left(E_{\text {act }}\right)$ for corrosion fatigue crack growth rates, evaluated on the basis of different investigations [7, 17, 28, 29] that are summarised in Arrhenius plot shown in Fig.2.

\begin{tabular}{|c|c|c|c|c|}
\hline Steel grade & $\begin{array}{c}\text { Temperature range } \\
{\left[{ }^{\circ} \mathbf{C}\right]}\end{array}$ & Region & $\underset{[\mathrm{kJ} / \mathrm{mole}]}{E_{a c t}}$ & ref. \\
\hline SM41A & 28-60 (elevated) & undefined & $9.0-14.4$ & Nagai [17] \\
\hline unalloyed $0,13 \% \mathrm{C}$ & 30-80 (elevated) & II & 17.5 & Telseren [28] \\
\hline $4360-50 \mathrm{D}$ & 5.5-13.5 (low) & $\begin{array}{l}\text { I } \\
\text { II }\end{array}$ & $\begin{array}{l}0 \\
14.7\end{array}$ & Cowling [29] \\
\hline $4360-50 \mathrm{D}$ & 5-20 (low) & $\begin{array}{l}\text { I (\& II?) } \\
\text { I } \\
\text { II }\end{array}$ & $\begin{array}{l}31.3 /^{*} \\
0 /^{* *} \\
18.6 /^{* *}\end{array}$ & Scott [7] \\
\hline $\begin{array}{l}* / \text { apparent value } \\
* * / \text { corrected value }\end{array}$ & & & & \\
\hline
\end{tabular}

